\title{
Radiofrequency Ablation: Four Decades Later, Still Optimizing Lesion Characterization
}

\author{
Alan Enriquez ${ }^{1}$ and Sharma Kattel ${ }^{2}$ \\ ${ }^{1}$ Yale University School of Medicine \\ ${ }^{2}$ Yale School of Medicine
}

February 26, 2022

Radiofrequency Ablation: Four Decades Later, Still Optimizing Lesion Characterization

\author{
Alan D. Enriquez, M.D. ${ }^{1,2}$; Sharma Kattel MD, PhD ${ }^{1}$ \\ ${ }^{1}$ Section of Cardiovascular Medicine, Yale University School of Medicine, New Haven, CT \\ ${ }^{2}$ VA Connecticut Healthcare System, West Haven, CT
}

Funding: None

Disclosures: Boston Scientific - Honoraria

Word count: 1304

Corresponding Author:

Alan D. Enriquez, MD

Cardiovascular Medicine

PO Box 208017

New Haven, CT 06520-8017

alan.enriquez@yale.edu

Intracardiac catheter ablation was first introduced in the early 1980s with a direct current shock used as the energy source. (1) Titration of energy delivery was difficult, and extensive tissue damage could occur. Radiofrequency (RF) ablation was first reported by Huang and colleagues in 1985 and has since become the cornerstone of catheter ablation. The technique and delivery of RF energy application has undergone significant modifications over the last two decades with the introduction of irrigated tip and contact force sensing catheters.

The current standard RF generator produces $300-750 \mathrm{kHz}$ of alternating sinusoidal current. During RF application, the current that transverses from the tip of the ablation catheter through intervening tissue to a dispersive electrode attached to patient's body surface results in lesion formation through resistive and conductive heating, with tissue temperatures $\geq 50^{\circ}$ Celsius resulting in irreversible injury. (2) As higher current delivery may be limited due to char formation from rapid temperature rise in the tissue-catheter interface, irrigated RF was developed to overcome this limitation. Introduction of contact force sensing catheters has provided an additional tool to continuously assess catheter stability during RF delivery, thereby improving safety and efficacy. (3) 
Despite these advances, assessment of lesion quality during RF ablation remains challenging, and inadequate lesion formation plays a substantial role in the relatively high recurrence rates after atrial fibrillation and ventricular tachycardia ablation. $(4,5)$ Current density is a primary determinant of lesion size and is dependent on multiple factors including RF power, size of the electrode tip, tissue contact, impendence, tissue-electrode interface temperature, tissue characteristics, and duration of energy delivery. Irrigated RF has rendered tip temperature unreliable as a predictor of tissue temperature, and accounting for all of these variables to reliably determine lesion size has been problematic.

As a result, there has been significant interest in developing algorithms to predict the size of lesion formation to improve efficacy and safety of catheter ablation. Force Time Integral (FTI) and Lesion Size Index (LSI) have been developed for use with the TactiCath ${ }^{\mathrm{TM}}$ contact force sensing catheter and Ensite ${ }^{\mathrm{TM}}$ Precision 3D mapping system (Abbott Medical, St. Paul, MN).

FTI is defined as total contact force integrated over the time of RF delivery. While targeting FTI $>400$ grams has been associated with improved outcomes in atrial fibrillation ablation (6,7), FTI does not account for power. LSI is calculated by aggregating contact force as well as current data across time with the intent to provide a more precise assessment of lesion formation. However, data regarding the accuracy of LSI in predicting lesion size and quality is sparse.

In this issue, Themistoclakis et al evaluated lesion size for pre-specified values of LSI reached during RF delivery in vivo in a porcine heart. Using 3D electro-anatomical mapping as a reference, $64 \mathrm{RF}$ lesions targeting LSI values of $4-6$ using a fixed power output of $30 \mathrm{~W}$ in temperature control mode at $42^{\circ} \mathrm{C}$ and contact force of 10-30 grams were created in 7 porcine hearts using a TactiCath contact force sensing catheter. The hearts were then explanted, and lesions were examined histologically. Only 25 non-transmural lesions were used for complete analysis with the remainder excluded due to transmurality, macroscopically unidentifiable lesions, or inability to measure lesion width or depth because of unfavorable anatomic location of the lesions. Of note, all atrial lesions were transmural with LSI $\geq 4$, and only lesions in the right and left ventricles were included in the final analysis. The authors were able to show a strong linear correlation with LSI values and lesion width $(\mathrm{r}=0.87, \mathrm{p}<0.00001)$ and depth $(\mathrm{r}=0.89, \mathrm{p}<0.00001)$. At LSI values of 4 , 5 and 6 , lesion width corresponded to $4.6 \pm 0.6 \mathrm{~mm}, 7.3 \pm 0.8 \mathrm{~mm}$ and $8.6 \pm 1.2 \mathrm{~mm}$ respectively. Similarly, lesion depth at LSI values of 4,5 , and 6 corresponded to $2.6 \pm 0.8 \mathrm{~mm}, 4.7 \pm 0.6 \mathrm{~mm}$ and $7.2 \pm 1.1 \mathrm{~mm}$ respectively. Furthermore, compared with other lesion parameters (FTI, RF duration, impedance drop, average temperature, contact force, and power), LSI was the only independent predictor of lesion width and depth in multivariable regression analysis. Also, steam pops, char formation, and damage to surrounding structures were not observed in this study.

This is the first in vivo study examining LSI and lesion width and depth, and the authors have demonstrated that LSI is highly correlated with lesion width and depth. Moreover, these findings are consistent with prior studies. A prior in vitro study using a porcine myocardial slab model also showed that LSI was predictive of lesion width and depth and was a stronger predictor compared to FTI (8). Another in vivo study by Whitaker et al showed that when a LSI of 5 is targeted in the right atrium of porcine hearts, a LSI(interlesion distance - LSI) $\leq 1.5$ was associated with contiguous lesions and no gaps in the ablation line. (9) Thus, this study supports LSI as a strong predictor of lesion size.

Achieving adequate lesion depth and width during RF application is important to obtain transmurality and contiguous lesions respectively and to improve efficacy of radiofrequency ablation. In some situations, it may also be important to limit lesion depth to prevent collateral damage to adjacent structures, such as avoiding esophageal damage when ablating in the posterior left atrium. Hence, LSI is a potentially powerful tool to assess lesion size during ablation in real-time. The authors proposed formulas for estimation of lesion width and depth using LSI based on their linear regression model $\left(W(m m)=-4.21+2.17^{*} L S I\right.$, and $\left.D(m m)=-7.54+2.54^{*} L S I\right)$. Using these equations, they proposed LSI values to achieve transmural lesions at different locations in the left atrium (LA) during pulmonary vein isolation (PVI) based on average human LA thickness (posterior wall $=4.1 \mathrm{~mm}$, LSI [?] 4.8; ridge between appendage and pulmonary vein $=5.0$ $m m, L S I$ [?] 5.2; or interatrial septum $=5.5 \mathrm{~mm}$, LSI [?] 5.4). There are clinical data supporting targeting 
pre-specified LSI values during PVI. There are small studies showing improved outcomes with PVI when the mean LSI achieved Is $>5.0$. (10,11) Kanamori et al showed that an LSI $<5.25$ anteriorly and $<4.0$ posteriorly was associated with conduction gaps after PVI and suggested target LSI values of $\geq 5.2$ anteriorly and $\geq 4.0$ posteriorly (areas adjacent to the espohagus) to obtain durable pulmonary vein isolation. (12) Adverse events were also not more frequent in patients with higher LSI values.

While the findings of this study are compelling, there are limitations in applying these LSI findings to clinical practice. There were a relatively small number of lesions included in the study, and there are inherent differences in tissue heterogeneity, thickness, blood flow, body surface, and impedance values in porcine hearts compared to human hearts. In addition, these findings are most applicable to ablation in the ventricles since atrial lesions were excluded from the final analysis due to transmurality, though LSI had similar correlation with lesion width in the atrial lesions. It is also important to note that these LSI values were obtained at a fixed power of $30 \mathrm{~W}$ and using saline irrigation. These correlations may not hold true for different power settings or other irrigation fluids (e.g. half-normal saline), especially with the use of high power due to nonlinear behavior of tissue heating from an initial rapid resistive heating in early phase to more conductive heating in the later phase.

The findings of this study combined with the existing literature support LSI as a clinically relevant surrogate for lesion size. Targeting LSI values of 4-6 appears to be safe, and LSI may be used as an adjunctive tool in conjunction with other parameters of RF ablation to estimate lesion size. However, caution must still be exercised, and there are no established LSI targets for atrial fibrillation and ventricular tachycardia ablation. While progress is being made in characterizing lesions during ablation, further studies are required to confirm the efficacy of using LSI and to establish optimal LSI target values.

\section{References}

1. Andrade JG, Rivard L, Macle L. The past, the present, and the future of cardiac arrhythmia ablation. Can J Cardiol 2014;30:S431-41.

2. Nath S, DiMarco JP, Haines DE. Basic aspects of radiofrequency catheter ablation. J Cardiovasc Electrophysiol 1994;5:863-76.

3. Yokoyama K, Nakagawa H, Shah DC, Lambert H, Leo G, Aeby N, Ikeda A, Pitha JV, Sharma T, Lazzara R, Jackman WM. Novel contact force sensor incorporated in irrigated radiofrequency ablation catheter predicts lesion size and incidence of steam pop and thrombus. Circ Arrhythm Electrophysiol 2008;1:354-62.

4. Packer DL, Mark DB, Robb RA, Monahan KH, Bahnson TD, Poole JE, Noseworthy PA, Rosenberg YD, Jeffries N, Mitchell LB, Flaker GC, Pokushalov E, Romanov A, Bunch TJ, Noelker G, Ardashev A, Revishvili A, Wilber DJ, Cappato R, Kuck KH, Hindricks G, Davies DW, Kowey PR, Naccarelli GV, Reiffel JA, Piccini JP, Silverstein AP, Al-Khalidi HR, Lee KL, Investigators C. Effect of Catheter Ablation vs Antiarrhythmic Drug Therapy on Mortality, Stroke, Bleeding, and Cardiac Arrest Among Patients With Atrial Fibrillation: The CABANA Randomized Clinical Trial. JAMA 2019;321:1261-1274.

5. Sapp JL, Wells GA, Parkash R, Stevenson WG, Blier L, Sarrazin JF, Thibault B, Rivard L, Gula L, LeongSit P, Essebag V, Nery PB, Tung SK, Raymond JM, Sterns LD, Veenhuyzen GD, Healey JS, Redfearn D, Roux JF, Tang AS. Ventricular Tachycardia Ablation versus Escalation of Antiarrhythmic Drugs. N Engl J Med 2016;375:111-21.

6. Neuzil P, Reddy VY, Kautzner J, Petru J, Wichterle D, Shah D, Lambert H, Yulzari A, Wissner E, Kuck KH. Electrical reconnection after pulmonary vein isolation is contingent on contact force during initial treatment: results from the EFFICAS I study. Circ Arrhythm Electrophysiol 2013;6:327-33.

7. Kautzner J, Neuzil P, Lambert H, Peichl P, Petru J, Cihak R, Skoda J, Wichterle D, Wissner E, Yulzari A, Kuck KH. EFFICAS II: optimization of catheter contact force improves outcome of pulmonary vein isolation for paroxysmal atrial fibrillation. Europace 2015;17:1229-35. 
8. Calzolari V, De Mattia L, Indiani S, Crosato M, Furlanetto A, Licciardello C, Squasi PAM, Olivari Z. In Vitro Validation of the Lesion Size Index to Predict Lesion Width and Depth After Irrigated Radiofrequency Ablation in a Porcine Model. JACC Clin Electrophysiol 2017;3:1126-1135.

9. Whitaker J, Fish J, Harrison J, Chubb H, Williams SE, Fastl T, Corrado C, Van Zaen J, Gibbs J, O'Neill L, Mukherjee R, Rittey D, Thorsten J, Donskoy E, Sohal M, Rajani R, Niederer S, Wright M, O'Neill MD. Lesion Index-Guided Ablation Facilitates Continuous, Transmural, and Durable Lesions in a Porcine Recovery Model. Circ Arrhythm Electrophysiol 2018;11:e005892.

10. Dello Russo A, Fassini GM, Casella M, Romanelli E, Pala S, Riva S, Catto V, Moltrasio M, Tundo F, Zucchetti M, Majocchi B, Dessanai MA, Pizzamiglio F, Vettor G, Ribatti V, Gasperetti A, Cellucci S, Negro G, Sicuso R, Carbucicchio C, Tondo C. Lesion index: a novel guide in the path of successful pulmonary vein isolation. J Interv Card Electrophysiol 2019;55:27-34.

11. Mattia L, Crosato M, Indiani S, Causin E, Licciardello C, Maria Squasi PA, De Leo A, Calzolari V. Prospective Evaluation of Lesion Index-Guided Pulmonary Vein Isolation Technique in Patients with Paroxysmal Atrial Fibrillation: 1-year Follow-Up. J Atr Fibrillation 2018;10:1858.

12. Kanamori N, Kato T, Sakagami S, Saeki T, Kato C, Kawai K, Chikata A, Takashima SI, Murai H, Usui S, Furusho H, Kaneko S, Takamura M. Optimal lesion size index to prevent conduction gap during pulmonary vein isolation. J Cardiovasc Electrophysiol 2018;29:1616-1623. 